\title{
ANALISA KADAR TIMBAL (Pb) PADA KANGKUNG AIR YANG DIPERJUALBELIKAN DI PASAR TRADISIONAL KOTA MAKASSAR
}

\author{
Nuradi \\ Jurusan Analis Kesehatan Poltekkes Kemenkes Makassar \\ nuradi.poltekkes.mks@gmail.com
}

\begin{abstract}
ABSTRAK
Penelitian ini dilatarbelakangi dengan banyaknya penjual sayuran misalnya kangkung air di pinggir jalan yang mengakibatkan adanya polusi logam berat dari asap kendaraan misalnya Timbal $(\mathrm{Pb})$. Timbal adalah logam berat yang bersifat toksik yang penetapan kadarnya dapat dilakukan dengan menggunakan spektrofotometer serapan atom (AAS). Jenis penelitian ini adalah observasi laboratorik dengan teknik pengambilan sampel secara random sampling. Penelitian ini dilaksanakan di Laboratorium Kimia Analitik Departemen Kimia Fakultas Matematika dan Ilmu Pengetahuan Alam Universitas Hasanuddin pada tanggal 12-13 juni 2017. Hasil penelitian ini menunjukkan dari 6 sampel terdapat 5 sampel yang memiliki nilai kadar Timbal yang positif. Dari pasar Pabaeng-baeng pagi 1.87 dan siang 0.96, pasar Tamalate pagi 2.79 dan siang 0.96, pasar Pettarani Sukaria pagi 0.95 dan siangnya tidak terdeteksi. Berdasarkan hasil penelitian yang dilakukan, maka dapat disimpulkan bahwa Kangkung air yang diperjual belikan di pasar Tradisional Kota Makassar memiliki kadar timbal (Pb), Pagi 1, Pagi 2, Pagi 3, Siang 1, Siang 2 dan Siang 3 adalah 1.87, 2.79, 0.95,0.96,0.96,0.00 $\mathrm{mg} / \mathrm{kg}$. persentase kadar timbal ada sekitar 83,3\% mengandung logam berat timbal $(\mathrm{Pb})$ dan $16,7 \%$ yang tidak megandung logam berat timbal $(\mathrm{Pb})$. Olehnya itu diperlukan perhatian khusus dari para pelaku industri untuk tidak membuang limbah yang mengandung logam berat berbahaya kedalam sungai, melalui berbagai kebijakan khusus.
\end{abstract}

Kata kunci : Timbal, Kangkung Air, Spektrofotometri Serapan Atom

\section{PENDAHULUAN}

Kangkung merupakan sayuran yang bernilai ekonomi dan persebarannya meluas cukup pesat di daerah Asia Tenggara. Beberapa negara yang merintis pembudidayaan tanaman kangkung secara intensif dan komersial adalah Taiwan, Thailand,
Filipina, dan Indonesia. Kangkung umumnya dikonsumsi oleh masyarakat Indonesia dan dapat menjadi salah satu menu di rumahrumah makan. (Rukmana, 1994).

Kangkung adalah salah satu jenis sayuran yang merupakan sumber gizi dan vitamin, produksi sayuran kangkung telah menjadi mata 
pencaharian sehari - hari di berbagai tempat dengan tingkat harga yang dapat dijangkau oleh berbagai kalangan masyarakat. Meskipun harga sayuran kangkung relatif murah, namun bila di tanam secara intensif dan berorientasi kearah agrobisnis akan memberikan keuntungan yang cukup besar bagi para petani. Kelebihan dari kangkung adalah karena tanaman ini memiliki daya penyesuaian yang luas terhadap berbagai keadaan lingkungan. Kangkung dapat tumbuh baik di dataran rendah maupun dataran tinggi. (Rukmana, 1994).

Tanaman dapat menjadi mediator penyebaran logam berat pada makhluk hidup karena masuknya logam tersebut pada tumbuhan melalui akar dan mulut daun (stomata). Sayur merupakan sebutan umum bagi bahan pangan asal tumbuhan yang biasanya mengandung kadar air tinggi dan dikomsumsi dalam keadaan segar atau setelah diolah secara minimal, pakan yang baik bagi manusia maupun hewan, asap kendaraan menyebabkan perpindahan logam yang kontaminasi di dalamnya seperti timbal, kadmium, kromium dan seng masuk ke dalam tubuh makhluk hidup lainnya. (Erdayanti, dkk, 2015).

Kangkung yang diperjualbelikan di lahan terbuka apalagi di pinggir jalan mempunyai resiko pencemaran yang cukup tinggi. Adapun salah satu pencemarannya yaitu pencemaran timbal, pencemaran ini dapat berasal dari asap kendaraan bermotor dan kegiatan industry lainnya. Mengingat bahaya akumulasi logam berat dalam lingkungan dan efek buruknya pada kesehatan, maka konsumen perlu pengetahuan tentang logam berat. (Widaningrum, dkk, 2007).

Sumber pencemaran timbal berasal dari asap kendaraan bermotor, industri, penambangan, pembakaran batu bara, peleburan biji logam, pembakaran sampah, dan cat tembok yang larut bersama air hujan. (Taihuttu, 2009).

Rahman et al (2007) dalam penelitiannya menggunakan Ipomoea aquatica Forsk (kangkung air) dan menyimpulkan bahwa tanaman ini mampu menyerap $0,558 \mathrm{ppm} \mathrm{Pb}$ sehingga tanaman ini memungkinkan untuk digunakan sebagai tanaman hiperakumulator $\mathrm{Pb}$.

Batas aman yang diizinkan oleh Direktorat Jenderal Pengawas Obat dan Makanan, yaitu sebesar 2 ppm. Kandungan $\mathrm{Pb}$ yang tinggi ditemukan dalam sayuran, terutama dalam sayuran hijau (Ditjen Pengawas Obat dan Makanan (POM) Departemen Kesehatan Nomor : 03725/B/SK/VII/89).

Efek toksik timbal terutama mempengaruhi otak dan sistem saraf pusat. Kadar timbal dalam otak dan hati dapat 5 - 10 kali dari kadarnya dalam darah. Akibat keracunan timbal antara lain gangguan sistem saraf pusat, gangguan saluran pencernaan, dan dapat juga timbul anemia. (Irianto K, 2013).

Peluang pemasaran kangkung makin luas karena tidak hanya dapat dijual di pasar-pasar lokal di daerah, tetapi juga telah banyak dipesan oleh pasar-pasar swalayan. 
Dengan masuknya sayuran kangkung ke pasar-pasar swalayan akan menaikkan harga jual sayuran ini.

Pasar tradisiona merupakan tempat bertemunya penjual dan pembeli serta ditandai dengan adanya transaksi penjual pembeli secara langsung. Bangunannya terdiri dari kios-kios atau gerai, los dan dasaran terbuka yang dibuka penjual maupun suatu pengelolah pasar.

$$
\text { Pada dasarnya pasar }
$$

tradisional ini sebagian besar menjual kebutuhan sehari-hari seperti bahanbahan makanan berupa ikan, buah, sayur-sayuran, telur, daging, kain, barang elektronik, jasa dan lain-lain. Selain itu juga menjual kue tradisional dan makanan nusantara lainnya.

Sistem yang terdapat pada pasar ini dalam proses transaksi adalah pedagang melayani pembeli yang datang ke stan mereka, dan melakukan tawar menawar untuk menentukan kata sepakat pada harga dengan jumlah yang telah disepakati sebelumnya. Pasar seperti ini umumnya dapat ditemukan di kawasan permukiman agar memudahkan pembeli untuk mencapai pasar.

Berdasarkan latar belakang tersebut, maka penulis telah melakukan penelitian tentang kadar timbal pada kangkung yang diperjualbelikan di beberapa pasar tradisional Kota Makassar.

\section{METODE}

Jenis penelitian yang digunakan adalah deskriptif yaitu penggambaran dari data penelitian secara kuantitatif untuk menganalisa kadar timbal pada kangkung air yang diperjualbelikan di pasar tradisional Kota Makassar dan dilakukan dengan teknik analisa laboratorik.

\section{Populasi, Sampel, Besar sampel dan} Teknik Pengambilan Sampel

Populasi dalam penelitian ini adalah kangkung air yang diperjualbelikan di pinggir jalan dibeberapa pasar tradisional Kota Makassar.

Sampel dalam penelitian ini adalah Sampel yang digunakan adalah kangkung air yang dijual dipagi hari dan disore hari masing-masing 3 sampel

Besar sampel dalam penelitian ini adalah 7 krim pemutih yang diambil di setiap penjual online di Kota Makassar.

Teknik pengambilan sampel dalam penelitian ini adalah diambil secara random sampling.

\section{Variabel Penelitian}

Variabel penelitian ini adalah kangkung air yang diperjualbelikan di pinggir jalan di beberapa pasar tradisional Kota Makassar.

\section{Tempat dan Waktu Penelitian}

Penelitian ini dilaksanakan di Laboratorium Kimia Analitik Jurusan Kimia FMIPA UNHAS pada bulan Juni 2017

\section{Prosedur Penelitian}

\section{Pra Analitik}

Alat Penelitian yang digunakan yaitu gelas kimia, labu ukur, botol sampel, batang pengaduk, Cawan Porselin, Tanur, Neraca Analitik, Pipet Volume, Corong, Hot Plate, Oven, lumpan sedangkan bahan 
penelitian yaitu kangkung air, Kertas Saring, Asam Nitrat $\left(\mathrm{HNO}_{3}\right) 60 \%$, Hidrogen peroksida $\left(\mathrm{H}_{2} \mathrm{O}_{2}\right) \quad 30 \%$, Timbal, Aquadest.

\section{Analitik}

a. Pembuatan Larutan Baku Timbal (Pb) 1000 ppm.

Serbuk $\mathrm{Pb}\left(\mathrm{NO}_{3}\right)_{2} \quad$ sebanyak 0,3966 g ditimbang dengan teliti dan dilarutkan dengan aquadets, selanjutnya dimasukkan dalam labu ukur $250 \mathrm{ml}$ dan volume larutan ditepatkan dengan aquadets. Larutan baku ini setara dengan 1000 ppm $\mathrm{Pb}$.

b. Pembuatan Larutan Baku Intermediate $\mathrm{Pb} 100$ ppm.

Larutan baku intermediet $\mathrm{Pb} 100$ ppm, dibuat dengan cara memipet $10 \mathrm{ml}$ larutan induk baku $\mathrm{Pb} 1000$ ppm, kemudian diencerkan hingga tanda batas dalam labu ukur 100 $\mathrm{ml}$.

c. Pembuatan Larutan Baku Kerja

Larutan baku $\mathrm{Pb} 100$ ppm dipipet ke dalam labu takar $100 \mathrm{ml}$ dengan variasi konsentrasi 0,$08 ; 0,24 ; 0,72$; 2,16 ppm selanjutnya diencerkan dengan aquadets hingga tanda batas.

d. Pembuatan larutan sampel

Ditimbang dengan teliti masing-masing 2 gram kangkung air kering setiap sampel kedalam cawan porselin, kemudian ditambahkan $\mathrm{H}_{2} \mathrm{O}_{2}$ $30 \%$ sebanyak $3 \mathrm{ml}$, dan ditambahkan $\mathrm{HNO}_{3} \quad 60 \%$ sebanyak $10 \mathrm{ml}$. setelah itu dipanaskan sampai kering sambil diadut, setelah itu diencerkan pakai aquadets sebanyak $5 \mathrm{ml}$, kemudian disaring masuk kelabu ukur 50 $\mathrm{ml}$ dengan menggunakan corong dan kertas saring. Setelah itu dibilas gelas bekas sampel dengan aquadets dan dituang kembali bilasan kedalam labu ukur menggunakan kertas saring, ditunggu sampai kertas saring benar-benar kering. Setelah itu, tambahkan aquadets sampai tanda tera labu ukur $50 \mathrm{ml}$, kemudian homogenkan selama 10 kali bolak balik, kemudian setelah itu hasil saringan tersebut dimasukkan kedalam botol dan ditutup sampai rapat. Setelah itu sampel diperiksa menggunakan alat Spektropotometer Serapan Atom (AAS).

e. Prosedur dan Pembuatan Kurva Baku

1. Di optimalkan alat SSA sesuai petunjuk penggunaan alat

2. Di ukur masing - masing larutan kerja yang telah dibuat pada panjang gelombang 324,8 nm

3. di buat kurva kalibrasi untuk mendapatkan persamaan garis regresi

4. Di lanjutkan dengan pengukuran contoh uji yang sudah dipersiapkan.

\section{Pasca Analitik}

Pengukuran logam timbal dengan menggunakan Spektrofotometer Serapan Atom 
a. Kedalam nyala udara asetilen diaspirasikan air dan alat pengukur dijadikan nol

b. Secara berturut - turut diaspirasikan larutan baku menurut bertambahnya konsentrasi

c. Nilai absorben larutan baku tersebut dicatat

d. Larutan sampel di aspirasikan ke dalam nyala yang sebelumnya telah diaspirasikan dengan aquadest untuk menolkan alat

e. Nilai - nilai absorben sampel dicatat

\section{Analisa Data}

Pada penelitian ini analisis data dilakukan secara deskriptif dan disajikan dalam bentuk tabel disertai narasi.

\section{HASIL}

Berdasarkan hasil penelitian diperoleh data tentang kandungan logam berat timbal $(\mathrm{Pb})$ pada tanaman kangkung air dapat dilihat pada tabel 1 dibawah ini.

\section{Tabel 1. Hasil Uji Kandungan Logam Berat Timbal (Pb) Pada Tanaman Kangkung Air}

\begin{tabular}{|c|c|c|c|}
\hline $\begin{array}{c}\text { Kode sampel } \\
\text { kangkung }\end{array}$ & $\begin{array}{l}{[\mathbf{P b}]} \\
\mathbf{m g} / \mathbf{k g}\end{array}$ & $\begin{array}{l}\text { Kadar batas } \\
\text { aman Pb pada } \\
\text { sayuran }\end{array}$ & Keterangan \\
\hline Pagi 1 & 1.87 & & Positif \\
\hline Pagi 2 & 2.79 & & Positif \\
\hline Pagi 3 & 0.95 & \multirow{2}{*}{$<0,8 \mathrm{mg} / \mathrm{kg}$} & Positif \\
\cline { 1 - 1 } Siang 1 & 0.96 & & Positif \\
\hline Siang 2 & 0.96 & & Positif \\
\hline Siang 3 & 0.00 & & Negatif \\
\hline
\end{tabular}

\section{PEMBAHASAN}

Logam berat sudah banyak terdeteksi pada sayuran, terutama yang ditanam dan dijual berdekatan dengan jalanan raya karena rentan polusi udara, antara lain yang berasal dari asap pabrik serta asap kendaraan bermotor, pembangunan yang sementara dibangun, limbah industri.

Dari hasil analisa logam berat $\mathrm{Pb}$ pada kangkung air yang terkontaminasi logam $\mathrm{Pb}$ pada kode sampel pagi 1 , pagi 2 , pagi 3 , siang 1 , 
siang 2, dan siang 3 konsentrasi kadar $\mathrm{Pb}$ adalah 1,$87 ; 2,79 ; 0,95 ; 0,96 ; 0,96$; $0,00 \mathrm{mg} / \mathrm{kg}$. Dari 6 sampel ada 5 sampel yang melebihi dari nilai normal $(83,3 \%)$ dan 1 sampel yang tidak mengandung logam berat $\mathrm{Pb}$ $(16,7 \%)$.

Berdasarkan analisis kandungan logam berat $\mathrm{Pb}$ pada tanaman kangkung air pada sampel pagi 1 sebesar $1.87 \mathrm{mg} / \mathrm{kg}$, sampel pagi 2 sebesar $2.79 \mathrm{mg} / \mathrm{kg}$, sampel pagi 3 sebesar $0.95 \mathrm{mg} / \mathrm{kg}$, sampel siang 1 sebesar $0.96 \mathrm{mg} / \mathrm{kg}$, sampel siang 2 sebesar $0.96 \mathrm{mg} / \mathrm{kg}$ dan sampel siang 3 tidak terdeteksi.

Suatu mekanisme lain yang dilakukan oleh tumbuhan Kangkung Air adalah toleransi. Menurut Fitter (1991), toleransi yaitu suatu mekanisme dimana tanaman dapat mengembangkan sistem metabolism yang dapat berfungsi pada konsentrasi toksik yang potensial, mungkin dengan molekul enzim. Berdasarkan beberapa penelitian, enzim, dinding sel, terutama fosfatase asam, telah diperlihatkan toleransi terhadap tingkat toksik ion-ion yang jauh lebih tinggi $(\mathrm{Cu} 2+, \mathrm{Zn} 2+)$ dalam ketahanan dibandingkan pada tanaman normal. Organ akar batang dan daun merupakan alat hara yang berguna untuk penyerapan, pengolahan, pengangkutan dan zat-zat makanan.

Berdasarkan hasil analisa data tentang kandungan logam Timbal (Pb) pada kangkung air yang di periksa menggunakan alat Spektropotometer Serapan Atom yang di laksanakan di Laboratorium Kimia Analitik Unhas maka didapatkan hasil bahwa lebih banyak kandungan logam Timbal $(\mathrm{Pb})$ yang terdeteksi pada kangkung air yang diperjualbelikan di pagi hari dibandingkan disiang hari. Pasar Pabaeng-baeng (pagi=1.87, siang 0.96), pasar Pettarani sukaria (pagi $=2.79, \quad$ siang=0.96), pasar Tamalate (pagi $=0.95$, siang $=0.00$ atau tdak terdeteksi). Maka dapat disimpulkan bahwa pada sayuran kangkung air lebih banyak terpapar logam berat Timbal dipagi hari dibandingkan disiang hari.

Standar legislasi batas aman untuk logam berat Timbal $(\mathrm{Pb})$ pada sayur yaitu West-German Federal Health Agency $(<0,8 \mathrm{mg} / \mathrm{kg})$, dan Regulation and Recommendation For Heavy (<2,0 ppm) (Ayu, 2002)

Dari hasil penelitian diatas bahwa standar legislasi logam berat pada sayur dari tabel 1 tanaman kangkung air yang diteliti tidak dapat dikonsumsi oleh masyarakat. Adapun pencegahan akumulasi logam berat pada tubuh manusia yaitu kesadaran gizi pada tingkat keluarga perlu ditunjang dengan pemahaman tentang masalah sanitasi sehingga cara pengolahan sayuran ditingkat rumah tangga bisa lebih aman dan memenuhi syarat kesehatan. Pada tingkat keluarga, usaha yang dapat dilakukan untuk menhindari bahaya logam berat dapat dilakukan antara lain mencuci sayuran dengan baik dan seksama, mencuci dengan menggunakan air yang mengalir, sayuran juga sebaiknya diblansir yaitu sayuran diberi pemanasan pendahuluan dalam suhu mendidih pada waktu yang singkat (3-5) menit yang bertujuan untuk mereduksi cemaran logam berat 
yang menempel pada permukaan sayur (Rukmana, 1994).

\section{KESIMPULAN}

Berdasarkan hasil penelitian
yang dilakukan, maka dapat disimpulkan bahwa Kangkung air yang diperjual belikan di pasar Tradisional Kota Makassar memiliki kadar timbal (Pb), Pagi 1, Pagi 2, Pagi 3, Siang 1, Siang 2 dan Siang 3 adalah $\begin{array}{llll}1.87, & 2.79, \quad 0.95,0.96, & 0.96, \quad 0.00\end{array}$ $\mathrm{mg} / \mathrm{kg}$. persentase kadar timbal ada sekitar 83,3\% mengandung logam berat timbal $(\mathrm{Pb})$ dan $16,7 \%$ yang tidak megandung logam berat timbal $(\mathrm{Pb})$.

\section{SARAN}

1. Melihat tingginya kandungan $\mathrm{Pb}$ pada tanaman kangkung air yang diperjualbelikan di pasar Tradisional Kota Makassar maka diperlukan pengawasan dari berbagai pihak mulai dari pemerintah, pelaku industri maupun warga setempat untuk lebih memperhatikan kebersihan lingkungan.

2. Diperlukan perhatian khusus dari para pelaku industri untuk tidak membuang limbah yang mengandung logam berat berbahaya ke sungai, melalui berbagai kebijakan khusus.

3. Pada penelitian selanjutnya diharapkan agar dilakukan pengukuran kandungan $\mathrm{Pb}$ yang terdapat pada air limbah, sehingga dapat diketahui koefisien penyerapannya oleh tumbuhan.

\section{DAFTAR PUSTAKA}

Adrian nur. 2012. analisa alat [internet] Available From: http://www.adrian_nur.staff. uns.ac.id. [diakses 26 Maret 2017]

Anonymous, 2000. Bahaya Kontaminasi Logam Berat Timbal pada Makanan. Sedap Sekejap Edisi 10/I, September 2000.

Darmono. 1995. Logam dan Sistem Biologi Makhluk Hidup. Jakarta Universitas Indonesia

Edy Smith Y, t.t. 2010. terapi sayuran pengobatan hemat dan aman dengan bermacam - macam resep tradisional

Erdayanti Pinta, T. Abu Hanifah, Anita Sofia. 2015. "Analisis Kandungan Logam Timbal Pada Sayur Kangkung dan Bayam Di Jalan Kartama Pekanbaru Secara Spektrofotometeri Serapan Atom", JOM FMIPA Volume 2 No.1 Februari 2015

Hassmiran. 2008. Analisis Kadar Timbal $(\mathrm{Pb})$ dalam Darah Pekerja Bengkel Motor yang terdapat di jalan Rappocini Raya Makassar. Makassar : Universitas Indonesia Timur

Haq Irsyadil. 2009. Identifikasi Kadar Timbal Pada Sawi Yang Diperjualbelikan Di Pasar Limbung. Makassar : Universitas Indonesia Timur

Irianto Koes. 2013. Pencegahan dan Penanggulangan Keracunan Bahan

Kimia 
Berbahaya.Bandung : Yrama widya,hal 30

Palar H. 1994. Pencemaran dan Toksikologi Logam Berat. Jakarta : PT Rineka Cipta

Priyanto. 2010. Toksikologi, Mekanisme, Terapi Antidotum, dan Penilaian Risiko. Jawa barat : Leskonfi, hal 112

Rukmana RH. 1994. Bertanam Kangkung. Jakarta : Kanisius
Siagian Prasetyo. 2011. laporan budidaya hortikultura kangkung. Jambi: Universitas Jambi

Siregar EBM. 2005. Pencemaran Udara, respon tanaman dan pengaruh kepada manusia.

Taihuttu H. N. 2009. "Kandungan Timbal Pada Vegetasi Jalur Hijau Jalan Di Dki Jakarta” Jurnal Budidaya Pertanian, Vol. 5. No 1, Juli 2009, Halaman 35-39 